HISPANIA. Revista Española de Historia, 2008, vol. LXVIII, núm. 229, mayo-agosto, págs. 315-340, ISSN: 0018-2141

\title{
EL ACEBO Y EL REY SIN FE*
}

\author{
EDWARD COOPER \\ ex London Metropolitan University
}

RESUMEN: La literatura científica sobre la explotación bajomedieval del alumbre, la sal de aluminio primordial en la economía europea cristiana, pasa enteramente por alto los recursos peninsulares del mineral explotados entre la caída de Constantinopla y la abertura de la empresa papal de Tolfa en 1463. Se identifican aquí cuáles eran estos recursos, indicando a la vez que el carácter geoquímico, teniendo en cuenta el ya estudiado yacimiento de Casacarrillo (La Rioja), era distinto a la formación volcánica de los depósitos clásicos de Toscana y Mazarrón. Se descarta la teoría corriente sobre la forma de localizar en el pasado los yacimientos alumbríferos, y se pretende colocar la breve bistoria pre-mazarronense de los alumbres españoles en el turbulento contexto histórico de la confrontación dinástica de mediados de siglo.

Palabras Clave: Alumbre. Jarosita. Cornago. Acebo. Mazarrón. Bergman. Beckmann. Tolfa. Ademuz. Albarracín. Juan de Luna. Juan II de Aragón. Volcánico.

\section{THE HOLLY AN THE KING OF LITTLE FAITH}

ABSTRACT: Research literature on the extraction of alum, the mineral salt basic to the economy of Christian Europe, entirely passes over the Iberian deposits in production between the fall of Constantinople and the commencement of the Papal operation at Tolfa in 1463. The sites of these are here identified, with an indication that their mineralogical formation is not that of the classic volcanic strata of Tuscany and Mazarrón. The much repeated theory on the way alum-bearing rock was located is shown to be suspect, and the pre-Mazarrón history of Spanish alum is given its context in the turbulent politics of the mid-century dynastic confrontations.

* Agradezco a D. ${ }^{a}$ Cristina Ferreira Fernandes, D. Ángel Antón Andrés, D. Fernando Cobos Guerra, D. Santiago Zaragoza Lozano y el personal del Instituto de Estudios Turolenses la ayuda prestada con entusiasmo en la preparación de este artículo.

Nótese $A A A=$ Archivo de la Comunidad de Aldeas de Albarracín; $A C A=$ Archivo de la Corona de Aragón; $A R V=$ Archivo del Reino de Valencia. 
KEY WORDS: Alum. Jarosite. Cornago. Holly. Mazarrón. Bergman. Beckmann. Tolfa. Ademuz. Albarracín. Juan de Luna. John II of Aragon. Volcanic.

Cuando publiqué con mi coautor, el mineralogista Salvador Mirete Mayo, La Mitra y La Roca ${ }^{1}$, quedábamos satisfechos de haber perfilado, entre otras cosas, la aplicación práctica en la Baja Edad Media de un mineral por entonces poco considerado, la jarosita ${ }^{2}$ y sus derivados. Nunca se nos ocurrió imaginarnos siquiera la importancia literalmente interplanetaria que iba a adquirir el tema en tres años. Lo único que sí podíamos intuir era que lo que se estaba desarrollando en el espléndidamente aislado término de Cornago a mediados del siglo XV no fue un fenómeno único, sino que lógicamente se iba a repetir en otras localidades hasta la fecha desconocidas. Por lo tanto, nos correspondía identificarlas. Logrado esto, con un mayor repertorio de datos, podríamos aclarar algunas de las cuestiones dejadas sin resolver definitivamente en nuestro primer intento: en particular, cómo se localizaron en pleno siglo XV estos depósitos minerales aparentemente sin antecedentes históricos, con qué tratamientos se convertía la materia prima en un producto comercializable, y quienes fueron los protagonistas de esta temprana actividad industrial más allá de los personajes que ya habíamos identificado. iQue los astrobiólogos llegaran a conclusiones más importantes, eso sería de propina (últimamente la jarosita se ha identificado en Marte)!

Los interesados en nuestra investigación se acordarán de que opinábamos que la atención prestada por el arzobispo de Toledo Alfonso Carrillo de Acuña (1413-1482) a las posibilidades mineras de La Rioja se enfocó, en primer lugar, no en la tan discutida ocupación de Cornago, sino en el mucho menos prometedor señorío de Jubera, propiedad de Diego Manrique, conde de Treviño, pero ocupado, como Cornago, por Juan de Luna, desde $1452^{3}$. En esa época, una base económica importante del arzobispado de Toledo eran las salinas giennenses del adelantamiento de Cazorla (la más desarrollada situada en Peal de Becerro, con otras dos en Iruela). El hermano del conde de Treviño, Rodrigo Man-

1 Cooper, Edward y Mirete Mayo, Salvador, La Mitra y La Roca, Toledo, Diputación, 2001. Es un lujo disponer de varias recensiones de un libro especializado, y nos resultó especialmente grato haber evitado críticas duras en las de GARCía TurZa, J., Berceo, 142 (2001), pp. 269-271, de Ayala CARCEDO, F. J., Boletín Geológico y Minero (mayo de 2002), pp. 111-112 y de Diago Hernando, M., Anuario de Estudios Medievales, vol. 32 núm. 1 (2002), pp. 531-2.

$2\left(\mathrm{SO}_{4}\right)_{4}(\mathrm{Fe} 2 \mathrm{OH})_{6} \mathrm{Ka}_{2}$. Es decir, sobrando hierro y faltando los átomos de aluminio para ser alumbre comercial, $\mathrm{K}_{2} \mathrm{SO}_{4}, \mathrm{Al}_{2}\left(\mathrm{SO}_{4}\right)_{3}+6 \mathrm{H}_{2} \mathrm{O}$. La jarosita además, es insoluble, característica que se tenía que eliminar para que su producto fuese de utilidad industrial. De hecho, como mínimo debe haberse realizado alguna transformación espontánea en el terreno por procesos naturales, para que se produjera en las aguas del entorno las propiedades que servían para orientar a los buscadores de antaño (COOPER, Edward y Mirete MAYO, Salvador, La Mitra y La Roca..., pp. 115 y 133-140).

3 CoOper, Edward y Mirete Mayo, Salvador, La Mitra y La Roca..., pp. 71 y 93. 
rique, conde de Paredes, intentó hacia 1451 socavar el regimen arzobispal del adelantamiento ${ }^{4}$. Ocho años más tarde, el arzobispo se desquitó, al facilitar a Álvaro de Zúñiga (posteriormente duque de Arévalo) una dispensa para poder casarse con Leonor Pimentel, tras haber engendrado varios hijos en la hermana de los dos Manriques.

Carrillo fue premiado con el castigo de Enrique IV y, pensando equivocadamente que le apoyaría Pío II, expresó después su frustración (pese a que el disparate había sido culpa suya) con un amargado recordatorio de su lema de 1436 stella tota sit bispaniae ${ }^{6}$, al comentar «en balde espero yo ayuda del Padre Santo contra las fuerças del rey, pues por dineros quiso que se perdiese la integridad católica de los reinos d'España» ${ }^{7}$. Al morir el conde de Treviño en 1459, siendo menor de edad su primogénito, se le proporcionó al arzobispo el momento ideal para intervenir en La Rioja, con la anulación regia el 4 de mayo de la posesión por Juan de Luna de Jubera.

No se conocen las circunstancias del inoportuno fallecimiento del conde. No hay nada que permita culpar ni siquiera indirectamente al arzobispo. Sin embargo, su desaparición le convenía extraordinariamente, y las consecuencias inmediatas son muy de su estilo: la condesa viuda intentó desheredar a su propio primogénito, llegando a incendiar la torre ochavada del castillo riojano de Navarrete, paradero de la documentación fehaciente de la sucesión del vásta$\mathrm{go}^{8}$. El motivo de la entristecida fue apoyar con las heredades de su hijo su escandaloso concubinato con el conde de Miranda, que de otra forma dependía de las rentas de su mujer Aldonza Avellaneda9. La afinidad de esta situación con el arzobispo consiste en el hecho de que el conde de Miranda era hermano del mismo Álvaro de Zúñiga.

Con los datos actualmente disponibles sigue siendo imposible documentar el momento en que el arzobispo transfirió a Cornago sus aspiraciones. Lo más probable es que coincida con las paces establecidas con los Manrique en marzo de $1461^{10}$. Teniendo en cuenta lo misterioso que es el aparentemente repentino descubrimiento de terrenos capaces de rendir alumbre en una zona que carecía de historia en este contexto, hemos opinado ${ }^{11}$ que la búsqueda de los minerales

4 García Guzmán, M.M., Colección Diplomática del Adelantamiento de Cazorla 1231-1495, Cádiz, 1991, doc. 208. Se puede sospechar también que el interés arzobispal en Atienza (COOPER, Edward y Mirete Mayo, Salvador, La Mitra y La Roca..., p. 43) llegó a ser al final frustrado, al desmembrarse las salineras con el término de Olmeda, para ser incorporadas al de Jadraque, señorío adquirido en 1469 por Pedro González Mendoza.

5 Galíndez de Carvajal, Lorenzo: Crónica de Enrique IV, cap. 35.

6 CoOper, Edward y Mirete Mayo, Salvador, La Mitra y La Roca..., p. 63.

7 Galíndez de Carvajal, Lorenzo: Crónica de Enrique IV, cap. 38.

8 CoOper, Edward y Mirete Mayo, Salvador, La Mitra y La Roca..., p. 72.

9 Señora de Iscar, en cuyo castillo el conde de Miranda guardaba a su amante (COOPER, E., Castillos Señoriales en la Corona de Castilla, Valladolid, 1991, p. 577).

10 CoOper, Edward y Mirete MAYO, Salvador, La Mitra y La Roca..., p. 54. Véase infra nota 88.

11 Véase supra nota 2. 
en la época del flogisto (como era el siglo XV) dependía en gran parte del análisis de las aguas. Aún habiendo dado así con la pista mineralógica a seguir, no iba a ser entonces nada instantánea la identificación de la zona explotable.

Otro libro reciente sobre el temprano desarrollo de la explotación del alumbre, un asunto de máximo interés para la historia de la ciencia en España, elaborado por el cronista oficial de Mazarrón, da o, mejor dicho, resucita una explicación distinta de la metodología de tan oportuno hallazgo en aquellos tiempos ${ }^{12}$. Hay que tenerlo en cuenta al asesorar la nuestra. El libro cubre, efectivamente, la edad de oro de la explotación, con un repertorio impresionante de documentación inédita del archivo municipal de Lorca. Sin embargo, es detectable una red de grietas en la confusa epistemología del autor.

Al hablar del histórico hallazgo de los alumbres de Tolfa (Italia) a principios de agosto de $1461^{13}$, dice:

«Pero en el año 1459 (sic) tendría lugar un descubrimiento que cambió el curso de la historia: cuando el mercader genovés Juan de Castro regresó de un largo viaje por Asia Menor (donde había estado comerciando con colores y telas), observó cómo en la región de la Tolfa romana existía gran cantidad de una planta llamada Ilex aquifolium, un arbusto que igualmente abundaba en las regiones alumbrosas de donde venía; por este sutil detalle consideró probable que la composición del suelo de la comarca italiana fuera igual o semejante al de aquellas tierras asiáticas. Sólo unos meses después los ensayos químicos confirmaron su hipótesis y la existencia de grandes depósitos de piedra aluminosa en Tolfa (Estados Pontificios) y en la isla volcánica de Ischia (Reino de Nápoles)»14.

La fuente especificada por el autor para estos datos es «M. Bergman: Disertación sobre la preparación del alumbre... Año 1789».

El historiador murciano expresa perfectamente la importancia histórica excepcional de los acontecimientos que pretende describir. Desgraciadamente, sin embargo, son erróneos tanto el recorrido de Giovanni da Castro, su patria chica, el papel atribuido al ilex aquifolium, la fecha del reconocimiento en Tolfa, y las circunstancias de la explotación de Ischia, como la identidad del autor, el título, el contenido y la fecha de publicación de la obra citada como fuente de la información suministrada. Pero para evitar más confusiones, hay que resolver las discrepancias en orden lógico. El dato clave, incluso para el mineralogista de hoy, es el supuesto valor del ilex aquifolium como indicador de la presencia del alumbre en el suelo.

En ese tiempo, no era del todo desconocido el yacimiento de alumbre en Ischia. Se había prohibido su entrada en el mercado durante la época del alumbre bizantino (anterior a la toma de Constantinopla por los turcos en 1453)

12 Guillén Riquelme, M.C., Un siglo en la Historia de Mazarrón 1462-1572, Mazarrón, 2001.

13 ZIPPEL, G., "L'Allume di Tolfa e il suo Commercio», Archivo della Real Società Romana di Storia Patria, vol. XXX (1907), pp. 5-51/ 17.

${ }^{14}$ Guillén Riquelme, M.C., Un siglo en la Historia de Mazarrón..., p. 5. 
porque la mediocre calidad amenazaba con perjudicar el precio del alumbre importado de Anatolia. Las minas fueron reactivadas necesariamente en 1459 no bajo Giovanni da Castro, sino bajo un genovés, un tal Bartolomé Pernix ${ }^{15}$.

La referencia primitiva sobre las actuaciones de Castro en Tolfa son los Commentarii del Papa Pio II, el mecenas de este pionero de los alumbres, que cuentan precisamente lo siguiente: «Per quos dum Iohannes ambulat, novam herbæ faciem offendit: miratur, inquirit, deinde certior similem nasci herbam in montibus Asiæ qui Turchorum ærarium alumine ditant (...)» ${ }^{16}$. No hace falta dominar el latín para dar cuenta de que aquí no hay ninguna mención de ilex aquifolium. Pero por menos inverosímil que sea esta versión, que la propuesta por el cronista de Mazarrón, no convenció ni siquiera a todos los contemporáneos: en el año anterior a lo de Tolfa, se había producido un hallazgo de alumbre en el término de Corneto, tierra natal de la madre de Giovanni da Castro, donde él se encontraba precisamente cuando le llegó por medio de un astrólogo un aviso sobre las posibilidades de Tolfa ${ }^{17}$. Bien se le pudo haber hecho creer al Papa que Giovanni da Castro había adquirido misteriosamente una memoria prodigiosa de todas las plantas gramíneas que había pisado en su vida, pues no le habría caído grato al pontífice ningún dato procedente de inanes astronomorum fabulce, dado el conocido desprecio de Pío II hacia estas fuentes según nos cuenta el biógrafo del siguiente Papa, Pablo $\mathrm{II}^{18}$.

Una relación de $1641^{19}$ pone en duda incluso las credenciales de Castro, aseverando que, lejos de ser un mercader retirado del comercio bizantino con motivo de la ocupación turca, había sido esclavo de un negociante turco del alumbre, y que la noticia del yacimiento de Tolfa fue comunicada en principio no al Papa, sino a Ludovico Frangipani, en ese momento señor de Tolfa, privado posteriormente de la posesión por presión del pontífice y de Fernando I de Nápoles. Así, hasta la leyenda de las «siete montañas de este mineral» expresada en los Commentarii puede ser pintoresca invención de Pío II. Lo que hace creíble tal interpretación es la continuada llegada a occidente de alumbre turco: el producto comprado en 1462 para los paños de Cuenca, por ejemplo, se califica de Lupay ${ }^{20}$. El suministro de este material de plena procedencia de tie-

15 Monti, P., Ischia - archeologia e storia, Salerno, 1979, pp. 477-8.

16 Libro VII, cap. 12 (ed. TOTARO, L., Commentarii, vol. II, Milán, 1984, p. 1452).

17 ZIPPEL, G., «L'Allume di Tolfa e il suo Commercio»..., pp. 5-51/ 17.

18 ZIPpel, G., «L'Allume di Tolfa e il suo Commercio»..., pp. 5-51/ 17.

19 Citado en BECKMANN, Johann, Beyträge zur geschichte der erfindungen, vol. 2 primera parte, Leipzig, 1784.

20 Iradiel Murugarren, P., Evolución de la Industria Textil Castellana siglos XIII-XVI, Salamanca, 1974, p. 184. Lupay quiere decir de Lopadion (Ulubat), en el litoral del mar de Mármara (JACOBY, D., «Production et Commerce de l'Alun Oriental en Méditerranée, $\mathrm{XI}^{\mathrm{e}}$ à $\mathrm{XV}^{\mathrm{e}}$ siécles», en: Borgard, P., Brun, J.P., Picon, M., L'Alun de Méditerranée, Actas del Coloquio Internacional Nápoles/Aix-en-Provence, 2005, pp. 219-267/237). La gestión pudo deberse a alguna intervención de parte del marqués de Villena. 
rras vedadas se debía en principio al pragmatismo turco-veneciano. Nada más despejados los escombros del asedio de Constantinopla, Mohamed II había firmado un tratado comercial con la Serenisima que seguía en vigor hasta las hostilidades de 1463, aunque, de nuevo, la suspensión de los negocios venecianos en el sultanato era, como mucho, momentánea. Se puede pensar, incluso, que cualquier interrupción que hubiera en la llegada a Barcelona o a Valencia del alumbre turco se debía más a la rivalidad de los genoveses, quienes habían logrado excluir, prácticamente, a los venecianos del Mediterráneo occidental ${ }^{21}$. Es más compatible con este desarrollo de los acontecimientos, que con la leyenda de los Commentarii, el retraso entre la caída de Constantinopla en 1453, cuando hubo indudablemente una escasez temporal de stocks de alumbre, y la aparición hacia 1459 de Castro, indudable experto en la materia, fuera cual fuera su recorrido anterior, para prospectar.

Pues si lo aseverado por el cronista mazarronense sobre el ilex aquifolium no procede de las fuentes más auténticas, tampoco da resultados inmediatos buscar su origen por «M. Bergman», que no existe. Se refiere seguramente a Torbern Olof Bergman (1735-1789), integrante del círculo sueco de la Ilustración radicado en la Universidad de Uppsala, cuyo miembro más conocido era el botánico Linneo. Bergman hubiera alcanzado igual renombre, de no haber fallecido a los 54 años de edad, siendo además todavía creyente en la teoría del flogisto — murió esperando que Lavoisier renunciara a sus teorías sobre el oxígeno- Era escritor prolífico, por cartas personales además de obras publicadas. Pero no he encontrado nada con el título citado por el referido historiador. El trabajo más pertinente del científico escandinavo en este contexto es Disquisitio Chemica de Confectione Aluminis, Uppsala, 1767. No contiene ninguna referencia ni al ilex aquifolium ni a Giovanni da Castro.

La serie de tratados de la cual forma parte la Disquisitio de 1767 fue publicada posteriormente en los diversos idiomas de los corresponsales de Bergman. Parece que no se carteaba directamente con nadie en España, aunque sí tenía a un discípulo español, el descubridor del wolframio Juan José de Elhuyar ${ }^{22}$, que desarrollaba su carrera de mineralogista en Venezuela. No había, por lo tanto, que se sepa, ninguna edición española de sus obras. La primera versión en la que se encuentra algo parecido a lo contado por el cronista murciano, es una traducción francesa, que dice:

«(...) Ischia (...) Dans le même temps Jean de Castro, qui avoit parcouru les fabriques de Constantinople, ayant vu à la Tolfa les houx qui croissoient sur les côteaux voisins de cette capitale de la Turquie soupçonna une semblable mine (...)»23.

${ }^{21}$ Iradiel Murugarren, P., Evolución de la Industria Textil Castellana siglos XIII-XVI..., p. 255.

22 RYDÉn, S., Juan José de Elhuyar en Suecia (1781-2) y el descubrimiento del tungsteno, Madrid, 1963 e Hidalgo CÁmara, E., «La Química Teórica y sus Aplicaciones», en: Peset ReIG, J.L., Historia de la Ciencia y de la Técnica en la Corona de Castilla, Valladolid, 2002, pp. 417-464/459.

23 Guyton de Morveau, L.B., Opuscules chymiques et physiques, vol. 1, Dijon, 1780, p. 304. 
Así se descubre que el ilex aquifolium es el acebo común, una planta tan extendida que es difícil imaginar que serviría para localizar un mineral, de cuyos yacimientos sólo ha existido una veintena de valor comercial importante en toda Europa. Es la versión inglesa, publicada 8 años más tarde, la que recoge que los datos históricos procedían no del mismo Bergman, sino de Johann Beckmann ${ }^{24}$; repite el relato de Pío II, añadiendo gratuitamente una referencia al ilex aquifolium, con la prevención de que la presencia de la planta no es fiable como indicador.

Es a través de Beckmann, sin embargo, que se llega eventualmente al final de la pista ${ }^{25}$. El equivalente italiano de Bergman, citado entre las muchísimas fuentes del enciclopédico sabio de Göttingen, fue Paolo Boccone (n. 1633), cuyo Museo de Física de 1697 fue publicado póstumamente en Venecia. Mantenía, como el omnisciente sueco, correspondencia erudita con intelectuales en diversas partes de Europa, entre ellos el romano Giovanni Battista Trionfetti. Sus declaraciones sobre la relación entre el acebo y el alumbre parecen haberse originado en su respuesta a una carta que le escribió éste en 1680 sobre el terreno de $\mathrm{Tolfa}^{26}$.

Pese a la conocida pericia del paduano Giovanni da Castro en la localización de los depósitos de alumbre, no era sino uno de los, por lo menos once, pioneros que de forma casi coetánea se dedicaron a esta actividad. En Italia, ya hemos encontrado al prospector genovés de Ischia, Bartolomé Pernix. Otro genovés, Biagio di Centurione Spinola, en el empleo de los venecianos, tuvo éxito en una prospección para el codiciado mineral en el Tirol austriaco, antes de pasar a primer director técnico en Tolfa al ponerse en marcha la explotación ${ }^{27}$. El descubridor del yacimiento de Casacarrillo (Cornago), todavía anónimo, hubiera podido ser otro, y fue aparentemente el también italiano Galeote de Negro, el descubridor primeramente de los efímeros depósitos de Cartagena y después, de los más duraderos pozos de Mazarrón²8.

Otra posibilidad en Casacarrillo fue García de Arín (el apellido que se entiende del latín del documento: seguramente es Ariño), vecino de Muniesa (Teruel), autorizado en Zaragoza, el 6 de abril de 1461, a entrar en producción con diversos metales que había descubierto en el reino de Aragón, y «aluminis viteroli sive de tierra de Sevilla» ${ }^{29}$. No se sabe exactamente qué puede ser este

24 tr. Cullen, Edmund, Physical and Chemical Essays, vol. 1, Londres, 1788, p. 341.

25 BECKMANN, Johann, Beyträge zur geschichte der erfindungen..., pp. 131-2.

${ }_{26}$ Boccone, Paolo, Museo de Fisica, Venecia, 1697, pp. 246, 249. Referencias a la fecha de su fallecimiento discrepan entre 1704 y 1707. Como otros tantos interesados en el alumbre era cisterciense.

27 ZIPPeL, G., «L'Allume di Tolfa e il suo Commercio»..., pp. 5-51/ 17.

${ }_{28}$ CoOper, E., Castillos Señoriales en la Corona de Castilla..., pp. 844-5. Es extraño el que Guillén Riquelme no haya dado con este dato.

29 ACA cancillería 3375 fols. 18v.-19. La Corona en concepto de impuestos: para el oro, la quinta parte; la plata, la séptima; otros metales, la duodécima, y aluminas viterolum, la novena. 
material, pero la terminología sugiere algo parecido al alumbre de Casacarrillo. Como Ariño es, hasta ahora, un desconocido total, hay que suponer que no llevaba inicialmente al ruedo profesional más formación que la que iba a tener como uno del pueblo. Es decir, una ciencia rústica, a base de depósitos existentes, en este caso, en el mismo término de Muniesa.

Pero como en 1461 Ariño no era un neófito en la prospección, y la Corona tenía establecida su correspondiente tarifa fiscal, es lógico vincular el comienzo de las operaciones mineras aragonesas con la política mediterránea del rey Juan II y, en particular, con la tregua conseguida con Génova en diciembre de $1458^{30}$. El gesto, para aplacar a los franceses, fue rápidamente frustrado por la invasión de Nápoles de Jean d'Anjou. Hubiera tenido, sin embargo, el efecto de romper las relaciones con los venecianos quienes, en ese momento, controlaban el ya limitado comercio del alumbre turco. Esto es el contexto de lo desarrollado al mismo tiempo en Ademuz (Valencia):

«Licencia investigandi alumen villa de Ademuz

Nos don Joan etc. como vosotros los justicia jurados oficiales e singulares personas de la nuestra villa de Ademuz tengays algunos vestigios e semblanças verdaderas que en algun lugar o lugares del termino de la dicha villa hay algunas rroquas mena o menas de alum de roqua e hayays voluntad de sacar e cauar la dicha mena por trobar el dicho aluz de lo qual se spera seguir vtilidat et prouecho a nuestra corte e gran beneficio e comoditat e prouecho a la dita villa lo qual fazer no oseys como no podays sin licencia e auctoridat nuestra por lo qual somos rogados por parte vuestra e humilmente supplicados la dita licencia vos quisiessemos otorgar. Nos hauiendo coharto a los servicios por la dita vniversidat a nos fechos e por seyer aquella puesta en muy cercano lugar de la frontera de Castilla e que de aquesto se vos spera seguir gran vtil como dicho es de que spereys reparar e adobar las murallas e socorrer ad algunas vuestras necesidades por los dichos guarides e otros que ado que esto nos induzen por tenor de la presente de nuestra cierta sciencia vos damos e otorgamos licencia facultat e permisso que sin mi correimiento de pena alguna podays en todo el termino de la dita villa inuestigar perquerir cauar o fazer cauar e busquar la dita rroqua o menas del dito alum de rroqua sin perdicion del derecho de otro alguno durant tiempo de diez anyos contaderos del dia que es feta principada la dita mena o inuestigacion de lo qual haya de constar por acto publico como aquel dia se principia. La qual gracia yncession o licencia vos damos e otorgamos con tal condicion que durante el tiempo sobre dito seays tenidos pagar a nos o a nuestro tresorero o bayle general del dito regno de Valencia o al bayle ordinario e local de la dita villa o al otro de ellos la ventena parte que salra o procedera de las dita mena o menas del dito alum sacadas empero primeramente las expensas del comun monton o acervo las quales fareys en el exercicio de las sobreditas cosas la qual ventena parte que como dicho es salvado el dito alum dareys e restituyreys de continente a los susditos o al otro de ellos en lugar nuestro o de nuestra corte. Et si caso sera que por vosotros era delliberado

30 Vicens Vives, J., Juan II de Aragón 1398-1479, Barcelona, 1953, p. 191. 
arrendar o tributar la dicha mena o menas paguedes el dicho venteno de despensas de lo que arrendeys a los susodichos o el otro de ellos con intervencion siempre del dito bayle de la dita villa en la dita arrendacion e tributacion antes los otorgantes que en cient passos alderredor de la dicha mena o menas ninguna presona no puede sacar inuestigar ni cauar otro metall alguno en el dicho vuestro termino dell so pena de dozientos florines de oro seays empero tenidos vosotros o la persona que por la dita villa sera dipputada el exercicio de las ditas menas o encara los cavantes o laborantes en aquellas prestar seguramente so homenatos en poder del dito bayle de la dita villa que en las sobreditas cosas (...) vtilidat (...) de la dita villa. Et que de qualesquiere cosas que salva e provechera de las ditas menas lo notifiqueys et notificaran de continente al antedito bayle local e dareys dara e daran buen leal e verdadero conto a los susoditos o al otro de ellos mandantes por las presentes a los por tanto veguer de governador bayle general del dito regne de Valencia e justicias jurados bayles e otros qualesquier officiales e subditos nuestros presentes (...) de los ditos officiales (...) a concession licencia e gracia a vosotros officiales e (...) e guarden tener e guardar e fagan e no contravengan o contra (...) e no permitan por alguna causa manera o razon antes en la execucion e exercicio de las ditas cosas vos den e presten todo consello necessario sera toda hora que por vosotros requeridos (...) fechas las presentes con el nuestro sello (...) seylladas dada en la nuestra ciudat de Çaragoça a veintesiete dias del mes de março del anyo de Mccclxi del nuestro regno de Navarra anyo treyntaseys de los otros (...) anyo quarto Rex Io.

Dominus Rex mayordomo michi Joannis Navarro visto por Ferdinandus de Trogillo $(\ldots) » 31$.

El negocio llevaba en marcha, en tanto que hay constancia, más de un año. Los ediles ademucenses, se supone que careciendo de los conocimientos adecuados para tal actividad, lo arrendaron a Martín de Reve y a Joan de Casal, maestro nuestro del alumbre (de Juan II de Aragón, rey de Navarra), encargado de la prospección y de la elaboración de alum de roqua ${ }^{32}$ en todas partes de Aragón y de Valencia por nombramiento del rey en Calatayud el 20 de septiembre de $1461^{33}$. En algún momento surgió una serie de desavenencias entre los interesados en el negocio ${ }^{34}$. No se reconciliaron pronto, y aprovechó el momento para intervenir el rey:

31 ARV Cancillería 286 fols. 46r.-47r. Documentos de esta procedencia se redactaban primero en latín, versiones en valenciano y castellano siendo normalmente traducciones y no textos originales. Es evidente que los escribanos encargados de la traducción no entendían a veces el original, o no sabían expresarlo en castellano. En estas versiones en romance, la fecha de expedición la añade normalmente otra mano. La pérdida de contraste en la tinta de este documento ha impedido sacar una transcripción continua. No obstante, está claro el sentido.

32 El término servía de pauta, refiriéndose a alumbre de la calidad de la procedente anteriormente de la zona de Edessa (Bizancio).

33 ACA loc. cit. 3376 fol. 46r. En este documento se le llama Joan Casals, forma no repetida en otras referencias.

34 Ibid. 3337 fols. 118v.-119r. El 14 del mes, Juan II había mandado a Antonio de Vintimiglia, baile de Castielfabib, que resolviera una disputa entre el magister aluminis de roqua y los frailes (de la orden de Montesa) en Ademuz. 
«El Rey

\begin{abstract}
Joannes de Casal
Procurador fiscal amado nuestro entendido hauemos no sin enojo y desplazer que de aqueixos dias passados hauiendo nos comendado todas las causas e quistiones asi mouidas como por mouer en la corte de la governacion del regno de Valencia entre Joan de Casal e Marti de Reue maestros de alumbre de roca agentes e deffendientes de la vna parte e Nicolau de Quintana mercader de la ciudat de Valencia de la otra al bayle e juez locales de la villa de Ademuz con ynhivicion para el dicho a la corte del governador e otros officiales nuestros estando los dichos Joan de Casal e Martin de Reve por virtud de nuestras provisiones en pacifica possession de la mena de alumbre que esta en el termino de aquella de villa de Ademuz la qual tiene arrendada por la dicha villa el xxiij del mes de febrero mas cerca passado vino vn portero de la dicha corte de la dicha governacion e no obstante la dicha nuestra inhibicion e mandamiento ocupo todo el alumbre que estaua fecho en la dicha mena e fizo ciertos otros actos por forma que el dicho Joan de Casal fue expellido de su pacifica possession de la dicha mena a los quales actos fazer los jurados de la dicha villa no temiendo encorrer las penas en la dicha nuestra commission apuestas dieron consello fauor e ayuda al dicho portero de que no solamente se dize han encorrido en las dichas penas mas en otras mayores e mas graves otrosi somos ynformados que por algunos de la dicha villa han seydo fechos ciertos insultos e actos de fecho contra el dicho Ioan Casal alborotandose contra el arojandole lanças e piedras por forma que si no se encerro en su posada le hubieran muerto e despues segund que dize han hinsidiado con ballestas armadas e cabriado por lo matar en tanto que le ha convenido dejar la dicha mena de que a nos e a nuestra corte se sigue assaz danyo e deservicio las quales cosas son assi graues e de mal exemplo E por tanto vos dezimos e mandamos tan estrechamente como podemos que vista la presente vayades a la dicha villa de Ademuz e en vno con el bayle e justicia locales de la dicha villa a los quales esto mesmo screpimos e mandamos recebir sumaria informacion de todas las cosas susodichas e aquella recebida la enbiedes closa e sellada al amado consellero e aduocado nuestro fiscal nuestro micer Pere Belluga al qual nos screuiremos lo que ha de fazer en estos negocios (...) dada en Tudela a xxvi de março anyo mcccclxii Rex Io»35.
\end{abstract}

Esto no dio satisfacción, debido en principio al incumplimiento de lo concertado por el mismo rey:

«El Rey

Justicia fiel nuestro por quanto nuestra voluntat es tomar a nuestras manos la mena del alumbre la qual de presente se lauora en la villa de Ademuç e que daquiavant aquella se deua obrar por nos e en nombre nuestro por el amado nuestro Joan de Casal maestro del dicho alumbre por tanto vos dezimos e mandamos tan strechamente como podemos que continente sin alguna otra dilacion o consultacion teneys a vuestras manos la dita mena e que aquella entreguedes e deliuredes

35 ARV cancillería 287 fol. 112. Otra versión en castellano, de la misma fecha, va dirigida al baile y justicia del reino de Valencia (ibid. fol. 118). 
al dito Joan de Casal que aquella obre por nos lançando a qualquiere otro detenidor o obrador de la dita mena teniendo e defendiendo al dito Joan Casal en la quieta e pacifica posesion de la dita mena e no fagays en contrario en alguna manera como esta sea nuestra incomutable voluntad e proposito. No entendemos en tiempo por la presente en res enbindicar ad aquexa villa la quantidat de los $\mathrm{M}$ e cinchcientos reales que aquella ha de hauer por el precio de la arrendicion que de aquella hauia fecho como por algunas iustas causas no queremos que dita arrendicion passe ni haya lugar dada en la nuestra ciudat de Çaragoça a xxiiij de mayo del anyo de mylCCCClxij Rex Jo»36.

La decisión del rey, de prescindir del consistorio ademucense en el arrendamiento de la explotación, se debe realmente a motivos de política peninsular. Habría tenido también en cuenta el evidente mal funcionamiento del negocio, y cita exigencias económicas ocasionadas por los acontecimientos en otras partes del reino:

«El rrey

Bayle amado nuestro nos hauemos deliberado tomar en nos la mena de Ademuç e pagar a la villa la arrendacion que de aquella ha fecho por aquest anyo Empero por quanto al presente con otrras necessidades no podemos supplir a pagar la meytat de los pertrechos segund era concordia fecha entre nos e Joan de Casal querremos que la dita mena se tome por el justicia de aquexa villa e sea entregada al dito Joan de Casal el qual la obre e responda al dezeno de lo que obrara franco de todas expensas fasta que por nos otra mena hi sea prouyedo por aquesto vos encargamos e mandamos que deys orden con el dito justicia como sea cobrada la dita mena e liurada al dito Joan de Casal e cobrareys e cullireys daquiauant la dezena parte de todo el alumbre que se fara por nuestro derecho dando orden que cosa de ella no se pierda dando especial cargo ad alguna persona que tenga sunent el allumbre que se fara por nuestro decimo no sea en res defraudado e en esto no fagays el contrario como esta sea nuestra voluntat dada en Çaragoça a xxvj de mayo de cccclxij Rex Jo»37.

No obstante estos óbices, al haber iniciado la explotación del alumbre en su término, los ediles de Ademuz no quedaron al final necesariamente destituidos de lo suyo por el rey sin fe. Teniendo en cuenta que habían sido incentivados en principio por la necesidad de pagar el mantenimiento de las defensas del pueblo frente a una posible amenaza castellana, lograron que se realizaran obras en el castillo bajo el alarife Pedro el Muet, de 1462 a $1470^{38}$.

El estancamiento de la empresa pudo deberse también a otras preocupaciones de los empresarios. Unas dos semanas y media antes del mandamiento de Tudela arriba citado, Joan de Casal había firmado en Calatayud un contrato

\footnotetext{
36 Ibid. 286 fol. 125 r.

${ }^{37}$ Ibid. fol. $125 \mathrm{v}$.

38 Ibid. Maestre Racional 9160.
} 
con Jaume Portugués para que este explotara un yacimiento de alumbre en Paracuellos de Jiloca, monopolio de Casal, durante un plazo de dos años a partir del 10 de enero ${ }^{39}$. Es decir, se trataba de una operación ya en marcha, de igual o mayor envergadura que la de Ademuz. El hecho de que Jaume Portugués era vecino de Ademuz sugiere que no le importaba a Casal despojar al negocio valenciano de su mano de obra especializada. Cabe sospechar que la iniciativa no evolucionó mucho mejor que la de Ademuz. La elaboración se iba a realizar en Ateca, probablemente porque la confluencia del Manubles con el Jalón producía más caudal de aguas que el Jiloca. Jaume Portugués se comprometió a avecindarse, con su mujer. Aparentemente, no lo cumplió.

Joan de Casal tuvo además un competidor, el escribano de Teruel y secretario real Juan Navarro, autorizado en Zaragoza el 11 de mayo de 1461 a buscar alum de Roqua y diversos metales en Aragón y Valencia ${ }^{40}$. Es lícito intuir que se desarrollara alguna rivalidad entre Casal y Navarro. No es impensable que se le ocurriera a uno de ellos en algún momento pasar al servicio del arzobispo de Toledo, si no fuese porque (aparte de sus propios compromisos, y la ya insinuada posibilidad de que se anticipara en esto García de Ariño) apareció pronto un intruso más capaz, incluso, de desempeñar tal papel:

«Don Joan por la gracia de Dios Rey dAragon de Nauarra de Sicilia de Valencia de Mallorques de Cerdenya e de Corcega comte de Barcelona duque de Atenas e de Neopatria e encara comte de Rossello e de Cerdanya: a los fieles e amados nuestros los (...) officiales de la ciudat e tierra de Sancta Maria de Albarrazin (...) salut e dilectio: por quanto nos hauemos fecho gracia e mercet al amado secretario nuestro Joan Nauarro de las menas de oro argento cobre e otros metales senyaladamente de la mena del alumbre que se fallara en los terminos de la dicha ciudat e tierra de Albarrazin con ciertas responsiones e cargos pagaderos por el dito Joan Nauarro en nuestra regia corte (...) como a nuestra noticia se a prouenido que Martin Valero notario vezino del lugar de Torres aldea de la dita ciudad sin alguna licencia e permisso nuestro con gran temeridad (...) hauria cauado e fecho cauar en el termino del dicho lugar de Torres vna mena de alumbre del qual ha vsado apurando e vendiendo aquel sin pagar derechos algunos (...) e por el interes del dito Joan Navarro por tenor de la presente (...) vos (...) mandamos dirigir in corrigimiento de la ira e indignacion nuestra e pena de mil florines de oro que de continente vayays al dicho logar de Torres e fagays mandamiento (...) asy al dicho Martyn Valero como a qualesquieres otros laboriantes en la dita mena con execucion de aquellas si el contrario han fecho que de aqui a mas no ossen obrar el dicho alumbre (...) sin voluntat e licencia mea (...) e por quanto el dicho Martin Valero ha obrado e fecho obrar el dicho alumbre (...) sin

39 Delante de Leonardo de Santa Fe, notario de Calatayud, en 8 de marzo de 1462 (RuBIO SEmper, A., «Un contrato de arrendamiento minero del siglo XV de Paracuellos de Jiloca», en: Actas del III Encuentro de Estudios Bilbilitanos, vol. II, Calatayud, 1992, pp. 199-201.

${ }^{40}$ ACA loc. cit. fols. 12-13. Juan Navarro tuvo una larga carrera al servicio del rey de Aragón, muriendo hacia 1480. 
(...) licencia (...) que dentro diez dias (...) comparezca dauant nos o nuestra audiencia real a mostrar con que titol o derecho ha obrado el dito alumbre e dar conta a nos o a nuestro thresorero de lo que ha recebido e exhigido del dito alumbre (...) dada en la nuestra ciudat de Calatayud a tres dias de agosto en el anyo de la natividat de nuestro senyor mil cccc lxj Rex

Dominus Rey vidavit Joannis Perpinyan vidavit Ferdinandus de Trugillo Rregis thesoreriae et Petrus Torrellas conservatores mayordomus michi Ffilipus Clementis $»^{41}$.

La contienda entre Juan Navarro y Martín Valero refleja lo que estaba ocurriendo en Ademuz. Pudo haber incluso una conexión más directa, con la posibilidad de que el portero referido en el documento del 26 de marzo de 1462 arriba citado fuera un agente de aquel. Además, en su capacidad de secretario real, es el mismo Juan Navarro quien expide los documentos del 27 de marzo de 1461, y del 24 y el 26 de mayo de 1462 arriba citados. Es decir, estaba tanto enterado como puesto al día respecto al alumbre de Ademuz. No solo eso: su hija Isabel, señora de Torre Somera (hoy en día Torre Alta, un aledaño de Ademuz) era viuda de Guido de Vintimiglia, pariente, probablemente, del baile de Castielfabib mencionado en la nota 34. En un día de marzo de 1462, el baile, con el señor del lindante Torre Fondonera (actualmente Torre Baja), Juan Ruiz de Castilblanch, y una fuerza de mudéjares y otros, intentaron expulsar a la viuda de su propiedad ${ }^{42}$. La torre de Torre Alta, un simple torreón bajomedieval de buena construcción (tiene una escalera de caracol), se conserva hoy en día, menos sus almenas. No es especialmente imponente, pero está ubicada con gran exactitud, controlando el cauce bajo del río Riodeva, crucial en la elaboración de los alumbres ademucenses, y su desembocadura en el Turia. Mantiene justamente, al mismo tiempo, visibilidad con el castillo de Ademuz en su altísimo peñasco ${ }^{43}$. Como se apreciará a continuación, los Navarro vigilaban efectivamente así la producción de los alumbres en Ademuz.

Estos acontecimientos pueden parecer suficientes para quitar la prioridad a la empresa riojana del arzobispo de Toledo. Sin embargo, hay más: en Zaragoza el 10 de marzo de 1461, el rey autorizó a Antonio de Thous a minar una

41 Ibid. 3337 fol. $102 \mathrm{v}$.

42 Hay dos versiones de la fuente documental de esta situación (ARV chancillería 287 fols.113 y 117v.-118r.): un mandamiento real en castellano al procurador fiscal del reino de Valencia, y otro en valenciano a Pere Belluga para que tomaran medidas, los dos de idéntica fecha y procedencia que los mandamientos a los mismos oficiales sobre el caso de Joan de Casal (supra nota 35). Difieren algo en los detalles: para Pere Belluga se omiten los mudéjares, pero es donde se descubre que la viuda es señora de Torre Alta. Lo que se entiende de la coyuntura es que, al morir Guido de Vintemiglia (sin hijos, se supone), Antonio de Vintemiglia quiso impedir que pasara la propiedad de su pariente al control de Juan de Navarro. Teniendo en cuenta la coincidencia de fechas, es muy probable que esto tenga algo que ver con las actividades de Joan de Casal.

43 El cerro ceñido por el castillo es, no sorprendentemente, el de Santa Bárbara, patrona de mineros. 
gama de substancias, incluso el alumbre, en los términos de Borriol, Artana y Orpesit ${ }^{44}$. Más allá de que ocurrieron el mismo tipo de hostilidades que en Torres de Albarracín, Ademuz y Casacarrillo, no se sabe nada de las operaciones. Otra posibilidad, como zona de yacimientos alumbreros identificada ya en el siglo XV, es Onda ${ }^{45}$.

Por falta de documentación concreta se ha de suponer que estas iniciativas pioneras carecían de consecuencias duraderas. La razón más obvia, en el caso de Ademuz, es que para llegar a Valencia, el emporio elegido y el único práctico para la producción realizada, las acémilas cargadas de alumbre tenían que cruzar un buen trecho de territorio castellano ${ }^{46}$. Es especialmente significativa en este contexto la identidad de quien mandaba en esa zona: desde hacía ya años había sido marqués de Moya y señor de Utiel (entonces castellano) Juan Pacheco, marqués de Villena. Habría sido imposible que un tráfico importante de mercancías saliera del Rincón de Ademuz sin ser inmediatamente visible desde la torre del homenaje del mismo castillo de Moya. Determinante, dadas esta topografía y sobre todo la fecha, es la real concesión al marqués de Villena el 24 de mayo de 1462 del monopolio de los alumbres del reino de Murcia, es decir, dos días antes de que Juan de Aragón quitara del control del consistorio de Ademuz la explotación de Joan de Casal para evitar, se supone, que ellos cayeran en la trampa de comprometerse con el marqués ${ }^{47}$. Desde luego, a éste no le interesaba para nada favorecer la empresa de Ademuz.

Se siguieron a continuación otros condicionantes previstos seguramente por los ediles de Ademuz en 1461, en particular el devastador tránsito por la zona de operaciones, especialmente la de Torres de Albarracín, de tropas enviadas

\footnotetext{
${ }^{44}$ Ibid. 286 fols. 39v. y 42v. «Orpesit» ha de ser Orpesita, un aledaño, se supone, de Orpesa/ Oropesa.

${ }_{45}$ No por ninguna documentación concreta, sino simplemente por la asistencia del comendador de Onda, fray Jacome del Bosch, como testigo y se supone, por lo tanto, interesado, a una autorización del baile general del reino de Valencia, Diego de Torres a mestre Gaspar Miracle y su compañía, a explotar depósitos minerales en todo el reino de Valencia. La licencia, fechada en 9 de mayo de 1498, toma forma de un contrato entre la autoridad y el interesado, en parte por la novedad, en Aragón en esas fechas, de esta actividad, y también, probablemente porque ya se hubiera determinado el yacimiento a desarrollar, y se podía prever un reparto de los beneficios entre el empresario y la Corona. El alumbre es uno entre varios minerales autorizados. Abunda en esa zona el caolín, capaz de dar alumbre mediante el proceso químico adecuado (hay que tener tambien en cuenta la presencia alrededor de Onda, por pobre que sea, de mineralizaciones de hierro en los terrenos del mucheskalck triásico). Acompaña al comendador un tal micer Ausias Bosch, doctor en Derecho. Puede ser un pariente, y su presencia servía seguramente para garantizar el rigor legal del documento (PÉrEZ PÉREZ, M.D., «Unos capítulos para la explotación de minas en el Reino de Valencia», en: V Congreso de Historia de la Corona de Aragón, vol. IV, Zaragoza, 1962, pp. 77-85).

${ }_{46}$ Cualquier tránsito directo desde el sur de Ademuz quedaba bloqueado por la impenetrable Sierra de Tortajada.

${ }^{47}$ Un día más tarde el marqués optó por compartir el privilegio con Pedro Fajardo Quesada, Adelantado Mayor de Murcia (CoOPER, E., Castillos Señoriales en la Corona de Castilla..., p. 834).
} 
por Enrique IV en 1464 a respaldar la causa de Pedro, condestable de Portugal, mascarón de proa de la rebelión catalana centrada en Barcelona contra el Rey $\sin f e$. Entre legítimas, aunque incontroladas, mesnadas del rey castellano, iban oportunistas saltados al carro del botín y saqueo. Otro presagio de la situación lo da perfectamente un asiento del Libro de Cuentas de la Comunidad de las Aldeas de la Tierra de Albarracín del año 1463:

«item que pone en data el dito papel que (Pedro Fuerte) fue a Gea (de Albarracín) por mandado de la ciudat e comunidat a fablar con el ssenyor Iohan Ferrandez (de Heredia, señor de Mora de Rubielos) capitan por cuanto avia venido hun honbre de Iohan de Albornoz con letra de Juan de Mariana diziendo que queria(n) entrar a rrobar a esta tierra Pedro Carrillo e Iohan de Albornoz que fuesse vna persona o dos alla a fablar con el dito Iohan de Albornoz e que por poca cosa que le diesen storvarian la entrada e mando el ssenyor capitan que no ffuesse ninguno sin que echassen spias de dentro de Castilla o en las fronteras $(\ldots) »^{48}$.

A 19 de diciembre, fueron debidamente despachados los especificados espías a Beteta y Poveda de la Sierra, señoríos de los dos próceres castellanos ${ }^{49}$.

Bien que cumplieron, los de Albarracín no se fiaron de la estrategia dictada por el representante del rey: tan precaria juzgaron la situación que el mismo día de Navidad

«fuy yo Pedro Ffuerte a Ueteta a fablar con Iohan de Albornoz secretamente a otra parte con Iohan de Mariana e Iohan de Rrodrigo por rrecomendarles sta tierra e si sentian ninguna cosa que nos auisassen secretamente e que la ciudat les daria para sendos jubones» ${ }^{50}$.

Después, «a vii de febrero (de 1464) fue vn hombre a Molina a Sante Yuste por sentir que le dizian que plegaua gente el conde de Medina y por sentir sy

${ }^{48}$ Cuentas de Pedro Fuerte, vecino del Villar, procurador de la comunidad de las aldeas de la tierra de Albarracín (20 de diciembre de 1463), fol. 10r. (AAA: cuentas de los años 1463-4, 14668, 1473-4 más algunos fragmentos que llegan hasta 1497. Su conservación se debe seguramente a la intención de poder mostrar a la Corona lo que había costado su apoyo y reclamar alguna recompensa. Los años que faltan son presumiblemente, por lo tanto, los que no evidencian el presumible gasto. El archivo se conserva en Tramacastilla y la consulta se puede efectuar sin dificultades a través de la copia en microfilm, disponible en el Instituto de Estudios Turolenses).

Juan Fernández de Heredia, señor de Gea, luchaba hacia 1468 con su pariente Fernando López de Heredia, señor de Santa Croche, llevando al asedio en un momento desconocido del castillo de Santa Croche por el futuro Rey Católico (ibid. fols. 117r. y 132r.).

49 Ibid. fol. 10v.

${ }^{50} \mathrm{Ibid}$. Se sabe por un asiento posterior (fol. 26v.) que Juan de Mariana era un simpatizante en el empleo de Juan de Albornoz. Los jubones son probablemente la forma de pagar los informes, más bien que el atavío reglamentario para el espionaje de entonces. 
saldra la gente por esta tierra» ${ }^{51}$. Algo tuvieron que aportar también Mariana y Rodrigo, pues a 18 de febrero los ediles de Albarracín enviaron a «dos espias a la torre de Motos sobre que dizian que venia ali Pedro Carillo por fazer caualgada» ${ }^{52}$.

Al final actuó decididamente Juan II: «a xxiiij de febrero (de 1464) vino hun correo del senyor rrey (mandando) que apartasen los ganados de las fronteras e guardasen las fortalezas» ${ }^{53}$. Lo que puede haberle incentivado es el hecho de que los hermanos Juan de Albornoz y Pedro Carrillo (m. 1493) eran hijos de un primo del arzobispo de Toledo (en abril de 1463, el primero, en efecto, había acompañado personalmente al prelado en el séquito de Enrique IV para verse en San Juan de Luz con Luis XI de Francia ${ }^{54}$ ). Siguiendo el mismo razonamiento, la "poca cosa» que se propuso ofrecerles, tan objetada por el capitán general, puede haber sido alguna explicación de cómo se elaboraban en Torres de Albarracín los alumbres, bien que el Libro de Cuentas no hace referencia a la actividad.

La situación exigió a los de Albarracín estrecha cooperación con Ademuz:

«a $\mathrm{x}$ de julio enbio el judez e la ciudat a Jaualoyas a Terriente que saliesen la gente ad Ademuz a guardar los puertos que no los (las tropas enviadas por Enrique IV) dexasen passar la via de Barcelona»s5.

Las medidas resultaron ineficaces: en algún momento llegó «hun correyo que vino de Castilla que traxo vna carta de la paz», pero a quince de julio se sabía que «la gente de Castilla auia passado a la tierra de don Jayme» ${ }^{56}$. Tal como hay que sospechar también en el caso de Ademuz, es evidente una discrepancia entre lo que se proponía en esta situación el Regimiento de Albarracín (pedía repetidamente autorización del capitán general para hacer correrías en la

${ }^{51}$ Ibid. fol. 43r. El conde de Medinaceli, recién llegado a la mayoría de edad, debía su sucesión en el condado a la intercesión del arzobispo. El castillo de Santiuste, al suroeste de Molina, era señorío del yerno del alcaide de Albarracín Juan Garcés de Marcilla.

52 Ibid. fol. 24r. Motos se situa al lado castellano de la frontera, al sur de Molina de Aragón. Como la encomienda santiaguista de Huélamo, que figura con frecuencia en las escaramuzas fronterizas de este tiempo, caía dentro del obispado de Albarracín.

53 Ibid. fol. 12v.

54 Galíndez de Carvajal, Lorenzo: Crónica de Enrique IV ..., cap. 48. También asistió en la misma capacidad el hermano del difunto conde de Treviño, el literato Gómez Manrique (no obstante ser hijo de un primo del marqués de Santillana, enemigo del arzobispo), y pudo haber estado también Pedro Carrillo, el menor de los dos hermanos, aunque no se le mencione. Juan de Albornoz no tenía descendencia, y se desavinieron posteriormente sobre la herencia.

${ }_{55}$ AAA. loc. cit. fol. 16v. Posteriormente «Gil Sanchez de Moscardon (...) fue como alcalde por la tierra por fazer sallir la gente via de Javaloyas diziendo que venian dozientos rrocines de Castilla para entrar en Aragon la via de Barcelona» (fol. 22r.).

56 Ibid. fols. 17v. y 18v. "Don Jayme» es, seguramente, Jaime Martínez de Luna, señor de Illueca y Morata. 
tierra de Molina de Aragón) y la política del rey, quien demandaba el envío de refuerzos para el asedio de Lérida ${ }^{57}$. Los ediles tenían por qué temer ya la posterior intervención del arzobispo de Toledo, pues "pago (Pedro Fuerte) al concello de Rodenas por mandado del comun por que les robo Lope de Cunya (...) trezientos quarenta rreales» ${ }^{58}$. De momento, por lo menos, prevaleció el consejo de Juan de Aragón, con tal que, en noviembre de 1464, mientras los regidores de Albarracín festejaban al mayordomo de Lope de Alarcón ${ }^{59}$ y a Carrillo, Pedro Fuerte fue personalmente a consultar con el cavallero de Motos ${ }^{60}$.

El Libro de Cuentas no explica que éste o es un seudónimo o es el apodo de Álvaro de Hita ${ }^{61}$. Como capitán de Enrique IV, llegó a ser en este tiempo enemigo encarnizado del arzobispo de Toledo. A principios de 1465, estando en Molina de Aragón con varios centenares de soldados,

«avia dado el rrey don Enrrique esta villa al duque de Alburquerque (...) y teniala por el Diego Hurtado de Mendoza (...) por do el arçobispo de Toledo ovo de embiar a Alvaro de Luna, hijo de Juan de Luna (el antiguo señor de Cornago, etc.), con docientas lanças (...) y (...) no embargante (...) fue avisado y rrequerido por algunos cavalleros que con el venian que llegase de noche (...) respondio que no pluguiese a Dios que tal cobardia demostrase que su voluntad era de ir de dia y pelear con quien quiera que resistirle quissiese. Venia con el Diego Cherino, que era capitan del obispo de Sigüenza por su mandado traia cincuenta lanzas, respondio que pesava mucho del mal consejo que tomava que una vez devia cumplir lo que le era mandado (...) Alvaro de Hita fue certificado de la venida de Alvaro de Luna (...) y comenzose la batalla de tal manera que Alvaro de Luna fue muerto (...) y Alvaro de Hita fue presso engañosamente y llevado a Torre de Almonagil donde Garci Mendez (de Badajoz) estava (...) y los de la villa (...) echaron de ella a don Diego Hurtado de Mendoza (...) y (...) la villa estuvo por el rey don Alonso (de Ávila), dada en tenencia al arçobispo de Toledo» ${ }^{62}$.

${ }^{57}$ Ibid. fol. 19v. En algún momento de 1464 Luis Muñoz tomó el castillo de Villel, el antiguo refugio templario al norte de Ademuz. No se sabe quien era. El capitán-general organizó el relevo (ibid. fol. 26).

58 Ibid. fol. 22v. Lope Vázquez de Acuña, el futuro conde de Buendía, era hermano del arzobispo de Toledo. El evidente acercamiento del arzobispo al rey de Aragón a partir de 1460 (infra nota 92) no fue suficientemente estrecho como para permitir a comprometerse la primicia aragonesa en la elaboración del alumbre.

59 Suegro de la hermana de Pedro Carrillo, y señor de las Veguillas, fronterizo de la sierra conquense del Escornadero. El motivo fue seguramente preguntarle cosas.

${ }^{60} \mathrm{Ibid}$. fols. 23r., $24 \mathrm{r}$.

${ }^{61}$ Su picaresca historia ha llevado a cierta mitificación de su imagen (LAYNA SERRANO, F., Los Castillos de Guadalajara, Guadalajara, 1994, $4^{\text {ta }}$ ed., pp. 475-8).

62 Galíndez de Carvajal, Lorenzo: Crónica de Enrique IV ..., cap. 72. El obispo de Sigüenza ha de ser Fernando de Luján, aliado del arzobispo, y no Pedro González de Mendoza, pues por las fechas en que este llegó a ser obispo seguntino (30 de octubre de 1467) sino bien antes, los Mendoza y sus deudos como, evidentemente, el duque de Alburquerque, eran implacables enemigos del arzobispo. Este dato aclara la fecha (Luján desaparece a mediados de 1465) y el desarrollo de los acontecimientos, aceptablemente relatados por el cronista, y confundidos por otros comentaristas. 
El encarcelamiento de Álvaro de Hita con García Méndez de Badajoz pone fuera de duda cuáles eran sus tendencias políticas: como indica su apellido adoptivo, es un incondicional de los Mendoza. No se sabe cómo logró recuperar la libertad, que al poco tiempo seguía disfrutando en el remoto paraje de Motos (se le reconoció tal vez el favor hecho involuntariamente al arzobispo eliminando al ya superfluo Álvaro de Luna). Desgraciadamente, faltan por entero las cuentas de la comunidad de las aldeas de Albarracín referentes al año 1465, que hasta ahora han ido dando las cruciales noticias inéditas. De todas maneras, en 1466 la situación daba señas de haber cambiado algo:

«a viii de março costo un correo que fue a Pozondon de la ciudat con vna letra que venia gente de Rrequena dos reales seis dineros....vn correo que enbio la ciudat a Cella a saber a do tiraua la gente que estaua alla de Aluaro de Mendoça costo dos rreales seys dineros» ${ }^{63}$.

Los de Albarracín pensaban entonces probar una nueva política para controlar este tipo de amenazas:

«a xiiii de jullio fueron a la ermandat de tierra de Molina a Tartanedo Iohan Perez de Argança e el procurador sobre saber como se fazian las hermandades (...) a xxi de de jullio vinieron los rregidores a la ciudat a oyr la relacion de Iohan Perez de Argança e del procurador sobre la ermandat e no vinieron syno Iohan Yvañez e Gil Sanchez».

Bien que esto no manifiesta un entusiasmo consistorial excepcional, hubo voluntad. Se notificó a Juan de Aragón el progreso efectuado, y el 19 de agosto, habiendo escuchado los otros dos regidores la relación de la excursión a Tartanedo, uno de ellos, Gonzalo González «fue a Alaua a tomar copia de los capitoles de la hermandat e a ssaber como se leuauan los de tierra de Teruel». Los promotores de la Hermandad fueron Antón Garcés y el regidor Juan de Sandalinas. A 5 de mayo de 1467 propusieron al consistorio escribir a los pueblos de Daroca, Calatayud y Teruel para que se asociaran, pero no hubo una aceptación inmediata de la idea. El acuerdo con Molina fue firmado en Ojos Negros el 20 de junio de $1467^{64}$. El caballero de Motos, entretanto, ya no era persona tan grata en la tierra de Albarracín:

El castillo de Almonacid era una encomienda de la Orden de Santiago, pero su proximidad a la Ciudad Imperial le recomendaba para cárcel arzobispal.

${ }_{63}$ Cuentas de 10 de diciembre de 1466, de Gonzalo Fernández Rajón, procurador de la comunidad de las aldeas de la tierra de Albarracín (AAA. loc. cit. fol. 44r.). El abuelo de Álvaro Mendoza, conde de Castrojeriz y señor de Requena, era cuñado de Jaime Martínez de Luna, y el conde era primo del padre del desgraciado Álvaro de Luna, víctima de asechanzas en Molina de Aragón.

${ }^{64} \mathrm{Ibid}$. fols. 47r., v., 48r., 75v. y 77v. (cuentas del 10 de diciembre de 1467 de Juan Cavero, vecino del Villar de Albarracín, procurador). En Álava, desde luego, el valiente Gonzalo González entró plenamente en el coto de los Mendoza. 
«a 22 de março (de 1467) fue Anton Garces a Motos a fablar con el cauallero sobre la gente que auia llegada por saber su voluntad (...) a xxii de abril fue Miguel Gomez de Saldon con vna letra de ciudat e tierra a Motos al cauallero por informarle los agrauios que fazian sus gentes (...) a xxviii de abril fue Iohan de Sandalinas a fablar con el cauallero de Motos sobre la gente que auia llegada a esta tierra» 65 .

Los ediles empezaron a tratar con el arzobispo de Toledo ${ }^{66}$. En julio de 1468 , circulaba un rumor de que iban a hacer correrías ladrones procedentes de Castilla ${ }^{67}$. Al mismo tiempo, se escondió Álvaro de Hita ${ }^{68}$. Las autoridades de Albarracín resucitaron la Hermandad, enviando capítulos a Moya, Salinas del Manzano, Teruel y Molina, y a Pedro Carrillo y Troilus Carrillo, hijo bastardo del arzobispo de Toledo que se encontraba en $\operatorname{Motos}^{69}$. Se puede suponer con este último detalle que ya no se explotaban ni el yacimiento de Ademuz ni el de Torres de Albarracín.

De hecho, a partir de la suspensión de las operaciones en Ademuz, iban a faltar entonces todavía probablemente tres años para que la iniciativa del arzobispo en la Rioja entrara en producción, permitiendo pensar que el avance pionero en la producción del alumbre en España tuvo lugar no en Castilla, sino en Aragón. Lo que precipitó probablemente la iniciación de la empresa alumbrera arzobispal del Linares fue el estallido de hostilidades entre los venecianos y el sultanato en 1463, causando escasez de la materia en el mercado. El funcionamiento efectivo de las operaciones a continuación parece marcarlo el salvoconducto otorgado por Juan de Navarra en Corella el 3 de marzo de 1464 al judío portugués Jorge Caro, servidor del arzobispo de Toledo, con sus 5 ayudantes, para poder circular libremente en Aragón, Navarra y Cataluña en servicio del

${ }^{65} \mathrm{Ibid}$. fols. $74 \mathrm{v} ., 75 \mathrm{r}$. En el asiento del 22 de marzo aparecen números arábicos.

66 Cuentas fechadas en 9 de diciembre de 1468 de Miguel Gómez, vecino de Orihuela del Tremedal, procurador etc., ibid. fols. 121v., 122r., 124r. Los asientos son de 1468, sin fecha específica.

${ }^{67}$ El 15 de julio las autoridades de Albarracín notificaron a las de Frías y el Villar la llegada de malhechores castellanos (ibid. fol. 128r.). Diez días antes había fallecido en Cardeñosa (Ávila) el príncipe Alfonso de Ávila. Los acontecimientos registrados a continuación parecen ser la reacción de los que, pretendiendo ser sus aliados, le habían manipulado para provocar la guerra civil en Castilla, en particular el arzobispo de Toledo.

${ }^{68}$ El primer indicio es el intento del procurador el 27 de julio de 1468 de poner espías en Orihuela del Tremedal y Bronchales para observar los movimientos del cavallero de Hita (ibid. fols. 123v. y 135v.). El 5 de agosto el espía Ferrant Catalán fue a Atienza e Hita para informarse sobre las fuerzas de que disponía Álvaro de Hita, que se había refugiado, aparentemente, en el Pobo de Dueñas (ibid. fol. 124r.) o en Torrubia (cerca de Molina). Tres días más tarde, sin embargo, seguía escondido (ibid. fol. 123v.). El 24 de agosto las autoridades de Molina y Martín de Salinas, agente del arzobispo de Toledo, admitieron a los ediles de Albarracín que no se le podía localizar (este Martín de Salinas no es el vecino de Alfaro testigo ocular de la muerte de Juan de Luna en el asedio de Lérida en 1464 (CoOper, Edward y Mirete MAYO, Salvador, La Mitra y La Roca ..., nota 23).

${ }^{69}$ AAA loc. cit. fols. 131v., 134v., 135r., sin más fecha que el año. 
arzobispo, "para fazer e rrecabdar algunas cosas e fechas que le cumplen e tractar algunas mercaderias ${ }^{70}$. El Rey tiene que haber estado enterado entonces de todo lo que estaba haciendo el arzobispo en el término de Cornago, pues los dos habían pasado juntos ${ }^{71}$ la fiesta de Navidad de 1463 en Corella ${ }^{72}$. Es imposible evitar concluir que Jorge Caro era el factor de los alumbres del arzobispo, el equivalente de Nicolau Quintana en el equipo de Joan de Casal, y que su cometido era llevar sus mercancias a Italia, pues el salvoconducto incluía entre los destinatarios «a los capitanes e patrones de nao e galeras e otras fustas que andan por la mar». Su nacionalidad dificultaría la interferencia directa de Juan de Aragón en el negocio. Se puede suponer, por otra parte, que, habiendo cesado en estas fechas la producción en Ademuz y Torres de Albarracín, ya no le importaba al Rey sin fe complacer a su aliado arzobispal.

Entretanto, los otros rivales comerciales indígenas de la iniciativa arzobispal de Casacarrillo iban a ser de hecho las explotaciones alumbreras de Xiquena, igualmente efímeras, y de Mazarrón, cuya fecha de comienzo es también desconocida. Se han notado las dificultades de producción, y la falta de documentación concreta sobre el funcionamiento de la empresa anterior a 1480. Sin embargo, en algo comerciaba en fecha temprana el copropietario de Mazarrón, Pedro Fajardo, adelantado de Murcia, pues en Prado del Rey, a 7 de julio de 1469, Juan II expidió otros sendos salvoconductos a los capitanes Alonso Montedoza y Alfonso Chinchones, mercaderes del dicho adelantado ${ }^{73}$. Corresponden tal vez a los primeros intentos de comercializar la producción del adelantado en Cartagena.

En principio, el arzobispo de Toledo era punta de lanza de la política diplomática de Enrique IV, específicamente en apoyo del príncipe de Viana en su contienda vitalicia con su padre sobre la sucesión navarra. El prelado tenía desde luego una historia de cambios de alianza, y el acontecimiento determinante

${ }^{70}$ ACA loc. cit. 3444 fol. 37r. Es lícito preguntarse si pudo haber una conexión entre Jorge Caro y Jaume Portugués de Ademuz.

${ }_{71}$ CoOPer, Edward y Mirete MAYO, Salvador, La Mitra y La Roca..., p. 83. El rey aragonés se habrá dado cuenta del papel del arzobispo en enero de 1463 al rechazar la propuesta de la embajada catalana en Almazán de sublevar la ciudad de Zaragoza para derribar el regimen de Juan II (Galíndez de CARVAJAL, Lorenzo: Crónica de Enrique IV ..., cap. 46).

72 De donde había mandado Juan II, el 23 de diciembre de 1463, a Fernando Lugones y a Gonzalo Conchillos, vecinos de Tarazona, que revisaran los estamiento y municion del castillo de Alcalá, dependencia del monasterio de la Veruela (ACA loc. cit. fol. 32 v.).

73 Ibid. 3449 fols. 78r, 79v. «Montedoza» es, seguramente, una aproximación aragonesa a «Montesdoca». Sobre la cronología de la producción de alumbre en España, las últimas publicaciones científicas repiten indiscriminadamente las aseveraciones de hace 30 años, por no decir también los errores: en Castilla «los primeros yacimientos se descubrieron en 1462 en Mazarrón y fueron inmediatamente concedidos en donación por mitad a los dos mayores señores jurisdiccionales del reino de Murcia: el marqués de Villena y el adelantado de Murcia, D. Juan Chacón (...)» (SÁNCHEZ GómeZ, J. y Pérez Melero, J., «Minería y Acuñación», en: López PiÑero, J.M., Historia de la Ciencia y de la Técnica en la Corona de Castilla, vol. III, Valladolid, 2002, pp. 467-501/483. Desde luego, el adelantado de Murcia en aquella época era Pedro Fajardo (véase nota 47 supra). 
en esta situación fue probablemente el intento de Juan II, casi inmediatamente después de la muerte de su hermano Alfonso V el Magnánimo el 28 de junio de 1458 , de procurar la promoción a la mitra de Pamplona del entonces abad de Santa Pía, Nicolás de Echávarri, integrante del bando agramontés ${ }^{74}$, previendo seguramente el regreso a la península del príncipe de Viana, privado ya de refugio en Sicilia, para buscar el apoyo del bando rival de los beamonteses. El asesinato $^{75}$ en Soria, a principios del año siguiente, instigado por Juan de Luna, de los conversos Alonso y Hernán Martínez de San Clemente, allegados del arzobispo, fue evidentemente un golpe en favor del todavía ausente príncipe.

Cómo pudo exactamente ayudarle este crimen trascendental se aclara a través de la persona de Gómez de Frías, consuegro de Juan de Luna y empeñado defensor de Alfaro contra las fuerzas pro-agramontesas del conde de Foix en $1463^{76}$. Siendo emisario de Enrique IV al príncipe de Viana en 1460 fue detenido por Juan $\mathrm{II}^{77}$. Fue portador seguramente de un sondeo de la oferta del rey castellano presentada por Pedro de Fuensalida y aceptada por el príncipe el 22 de abril de 1461, de la mano de la princesa Isabel, que tenía entonces 10 años. La dote incluía Soria. Se puede adivinar que la idea no fue una total novedad, y que los San Clemente encabezaban la oposición local a la enajenación de su ciudad al reino vecino. No fue para nada que Juan de Luna fuera el heredero del simbolismo antiaragonés (y en este caso pro-navarro) de su suegro, el difunto condestable ${ }^{78}$. Es lógico por lo tanto la actuación, a continuación, de Juan II para quitar a los partidarios del príncipe el ascendiente conseguido en el centro ganadero de la meseta: instaló, no se sabe cómo, a su incondicional agramontés Pierres de Peralta en el inexpugnable castillo de Soria, y el 4 de abril de 1459 previene ${ }^{79}$ al asesino Juan de Barrionuevo y al hermano de su

${ }_{74}$ En Zaragoza, el 14 de agosto de 1458, el nuevo rey de Aragón informó a su procurador en la curia romana, Francisco Ferrer, deán de Tudela, que había solicitado al Papa la transferencia de la abacía de Santa Pia al capellán del futuro Rey Católico, Amaneo de Mauleón (menor de edad), hijo del camerlengo Charles de Mauleón, si se consiguiera el nombramiento de Echávarri a la vacante de Pamplona (ibid. 3362 fol. 11r., y COOPER, Edward y Mirete MAYO, Salvador, La Mitra y La Roca..., p. 84). En esta ocasión el apoyo a Echávarri es infructífero, pero el fallo no es óbice a que Juan II siga favoreciéndole, pues el futuro obispo es nombrado, con el de Vich, para dictaminar en el caso de una disputa sobre la colegiata de Tudela (ACA loc. cit. fol. 86).

75 CoOper, Edward y Mirete MAYO, Salvador, La Mitra y La Roca..., p. 20.

76 El editor de la indispensable edición de la Crónica de Enrique IV que he manejado, J. Torres Fontes, le llama, equivocadamente, «Gómez de Rojas» (cap. 73), un absolutamente atípico error de transcripción.

77 ViCEns Vives, J., Juan II de Aragón..., p. 220.

78 Diago Hernando, M., «El alcaide Juan de Luna: un hombre al servicio del Condestable don Álvaro en la región soriana», Celtiberia, 81-2 (1991), pp. 59-85. Ideológicamente, es comprensible, aunque no exactamente elogiable, el que Luna buscara consolación adúltera en el seno de la viuda del Condestable.

79 En Valencia (ACA loc. cit. fol. 46). Se envía también copia a Juan de Luna, instigador de los asesinatos. Éste es, en primer lugar, el destinatario más lógico de este mandamiento, pero la probabilidad 
madrastra Pedro González de Mendoza el malo, de obstaculizar los intercambios comerciales por el sector fronterizo de Ariza.

El malo dispone, a través tal vez del obispado de Calahorra, en manos entonces del nieto del hermano de su cuñada, o por amenazas directas ${ }^{80}$, de la influencia para lograr a corto plazo que se le entregue a él mismo el castillo de Soria ${ }^{81}$. Pero Juan de Luna, perseguido por la justicia de Enrique IV, ya se encuentra en tierra de nadie: Juan II, pensando tal vez en convertirle en peón político, le concede un salvoconducto para entrar en Aragón con 40 seguidores $^{82}$. Las condiciones estipuladas pudieron disuadirle de valerse entonces de la licencia, y puede ser que el episodio de Montalbán ${ }^{83}$ tuviera lugar en ese momento. De hecho, no hay noticias concretas de su presencia en Aragón hasta mediados de 1460, cuando escribe a Juan II. El 11 de junio el rey, en ese momento en Barcelona, acusa recibo, sin comprometerse a una contestación definitiva "pero speramos de dia en dia el abbat de Santa Pia el qual venido soys sobre aquellas (cosas) por nos auisado de nuestra voluntad (...) $)^{84}$. Luna se encontraba entonces alojado en los dominios de su enviudada hermana Leonor, habiendo garantizado no intervenir en la disputa de su sobrino Felipe de Castro con el camarlengo Rodrigo Rebolledo. No guardó su palabra, y la situación empezó a volverse grave con su implicación en la llegada de fuerzas armadas alrededor de Barbastro, apoyadas por Jofre de Castro (otro tío de Felipe de Castro) y por elementos venidos de Cataluña ${ }^{85}$.

Se nota, al mismo tiempo, la continuada ascensión política de Nicolás de Echávarri, a quien le faltan todavía casí dos años para llegar a obispo de Pamplona. En los acuerdos que preceden la capitulación a Juan II del asediado reducto beamontés de Cervera (18 de julio de 1465), se han de entregarle al ya

es que, encarcelado temporalmente a consecuencia de los crímenes y excluido de Cornago, se hubiese escondido, tal vez en los señoríos de Pedro González el malo, al igual que Juan de Barrionuevo.

${ }^{80}$ En Valencia, el 30 de abril de 1459 Juan II manda al baile general de Aragón que haga suprimir las correrías de Juan y Sancho Heredia, Juan Pérez Calvillo y Fernando Vicente en apoyo de Pedro González de Mendoza y de Juan de Luna (ibid. 3408 fol. 2v.).

${ }^{81}$ Mandamiento de Juan II a Pierres de Peralta, dado en Valencia a 29 de abril de 1459 (ibid. 3407 fol. 104, con copias a Pedro González y al mensajero de mosén Rodrigo de Bobadilla).

${ }^{82}$ Dado en Valencia, el 16 de junio de 1459 (ibid. 3367 fol. 28v.). Con reveladora astucia el rey excluye específicamente del permiso a Juan de Lezcano (nombrado 12 días antes alcaide de Luesia) y a «Pedro», tronpeta del príncipe de Viana.

83 CoOper, Edward y Mirete MAyo, Salvador, La Mitra y La Roca..., p. 23. De hecho, toda la cronología de las acciones de Juan de Luna desde la muerte en 1453 del condestable Álvaro de Luna es susceptible de una revisión, pues es evidente que su enlace con la viuda empezó en vida del primogénito de este (COOPER, Castillos Señoriales..., p. 972), habiendo sufrido ya su propia esposa al menos seis años de infidelidad al hacerse efectiva la separación definitiva.

${ }^{84}$ ACA loc. cit. 3409 fol. 59.

85 Noticia del 26 de agosto de 1460 (ibid. fols. 161-2). Entre otros oficios, Rebolledo era pagador de las galeras de la Corona. 
entonces obispo las fortalezas de San Juan de Pie del Puerto, Tiermes y Ezco ${ }^{86}$. La tenencia es mediante reembolso de sus gastos. La coyuntura, en pro de la tendencia agramontesa, apoya la acusación al obispo de complicidad con el conde de Foix en la invasión francesa de Navarra en $1463^{87}$.

El arzobispo de Toledo, mientras tanto, entraba en el círculo del rey de Aragón más circunspectamente de lo que parece indicar en principio el cronista, con referencia al año nuevo de 1460:

«estando el rey (Enrique IV) alli (en Segovia) fue avisado como el rey don Juan de Aragon se avia confederado con el almirante, su suegro, y con don Alfonso Carrillo, arçobispo de Toledo, y con el maestre don Pedro Xiron, y con todos los Manrriques» 88 .

Un indicio del favorecimiento del arzobispo por el rey aragonés se contiene en el requerimiento regio del apoyo de la condesa viuda de Medinaceli para el nombramiento del nuevo abad de Sta. María de Huerta ${ }^{89}$. El 3 de diciembre, el arzobispo es destinatario ${ }^{90}$ del aviso de Juan II de la detención de su primogénito Carlos en el palacio real de Lérida, con su incondicional Juan de Beaumont, por haber procurado sin permiso su desposorio con la infanta Isabel de Castilla. El año siguiente Juan II le nombra procurador para tratar con Enrique IV sobre la movilización de tropas castellanas en la frontera navarro-aragonesa ${ }^{91}$.

86 Zurita, Jerónimo, Anales de la Corona de Aragón, XVIII - iii; edición de Canellas LópeZ, A., Zaragoza, 1988.

87 CoOper, Edward y Mirete Mayo, Salvador, La Mitra y La Roca..., p. 85. De todas maneras, la fuente, Galíndez de Carvajal, se equivoca del año, atribuyendo los acontecimientos a 1465. Como Galíndez, Zurita se confunde también acerca del año del asesinato del obispo (ZURITA, Jerónimo, Anales de la Corona de Aragón..., XVIII - xxiii).

88 Y otros (GALÍndeZ de Carvajal, Lorenzo: Crónica de Enrique IV..., cap. 36).

89 Juan de Magdalén, abad de Fonsa Nova (Zaragoza, a 27 de julio de 1460 (Archivo de la Corona de Aragon loc. cit.. 3442 fol. 24v.)). La disposición de la condesa a cooperar fue comprometida seguramente por la despoblación del condado de Medinaceli registrada en 1453, un mes después del ajusticiamiento de Álvaro de Luna (Archivo del ducado de Medinaceli, Medinaceli 50-4), a consecuencia de la recuperación de Villarroya de la Sierra por Juan de Aragón. En 1459, temiendo seguramente que su primogénito seguiría la política pro-aragonesa de su suegro, llevando al exilio en Aragón de su marido, pretendió desviar la sucesión en el condado, quedando obstaculizada por el arzobispo. La fraseología utilizada por Juan II reconoce expresamente la titularidad del hijo, protagonizada por Carrillo. El motivo del rey fue hacer llegar a un sobrino la abadía de Fonsa Nova (hoy Fossa Nova, cerca de Roma, donde murió Santo Tomé). La localización del cenobio soriano de Santa María de Huerta (cisterciense), pegado a la frontera aragonesa, le dio gran importancia estratégica en esa época.

90 Con los demás de la ya tenue facción pro-aragonesa, faltando Pedro Girón (ACA loc. cit. fol. 204v., dado en Lérida). Juan de Beaumont tuvo entonces el sentido común de buscar la protección de Enrique IV, y una vez fallecido el príncipe de Viana el 23 de septiembre de 1461, Juan II no tenía especial necesidad de hacerle asesinar también, suerte que no corrió otro allegado del príncipe, Narciso Miguel, abad de Ripoll, envenenado en 1460.

${ }^{91}$ En Santa Fe (cisterciense) el 8 de julio de 1461 (ibid. 3410 fol. 199). Rodrigo Rebolledo es 
De hecho, la liga formada a principios de 1460 había sido de poca duración, pero el rey aragonés pensaba perseverar con el arzobispo, cuyo emisario Martín de Salinas, vecino de Molina de Aragón, le visita dos veces en los siguientes meses ${ }^{92}$. Antes, probablemente, de la segunda visita, Lope Vázquez de Acuña, el previamente referido hermano del arzobispo, también entra en Aragón con el conde de Paredes, el hermano del difunto conde de Treviño ${ }^{93}$, con lo cual parece que Juan II había efectuado algo inverosímil, la reconciliación de los Manrique con Alfonso Carrillo ${ }^{94}$.

La dependencia mutua fue reforzada en 1464 al traspasar Enrique IV Jubera, patrimonio del conde de Treviño y antes efímera posesión de Juan de Luna, a García Méndez de Badajoz, al mismo tiempo que entrega Cornago, demandado por el arzobispo, a Juan de Beaumont. Una consecuencia directa, se puede suponer, es que en enero-febrero de 1465, el otro hermano de los dos condes, Gómez Manrique, amistado desde hacía dos años con el arzobispo, llega a capitanear sus fuerzas en la toma de Molina de Aragón, frustrando con ella las ambiciones de sus propios parientes ${ }^{95}$.

Está preparado así el terreno para que el arzobispo coopere con la Corona aragonesa en confiscar los bienes de Juan de Luna, de cuyos herederos Carrillo intenta arrebatar el señorío de Cornago. El 30 de mayo de 1464, Juan II autoriza el desembargo de los bienes en favor de Álvaro de Luna, primogénito del reo ${ }^{96}$. El gesto es importante, pues explica con mucha más precisión de crono-

uno de los testigos de la gestión. El rey castellano había pretendido que las mesnadas correspondían a tensiones internas (ibid. fols. 128-9), específicamente la crisis sucesoria en el condado de Treviño (COOPER, Edward y Mirete MAYO, Salvador, La Mitra y La Roca..., p. 72), y al asesinato de Diego de Vergara, cuyas circunstancias no han sido aclaradas.

92 Salvoconductos expedidos en Olite el 14 de abril de 1460, y Zaragoza el 6 de diciembre de 1461 (ACA loc. cit. 3370 fols. 141-2 y 3375 fol. 150v.). Muy poco después de la primera visita ocurre lo que parece ser un intento de imponer en el cabildo catedral de Pamplona a un canónigo castellano, un tal Juan de Bobadilla, según referencias del 29 de mayo de 1460 (el príncipe de Viana, en Barcelona, como lugarteniente de su padre, exige el nombramiento al «religioso» (se supone Echávarri), a su hermana Leonor y al cabildo pamplonés. Se desconoce el resultado (ibid. 3498 fol. 44)).

${ }_{93} \mathrm{Ibid} .3410$ fol. 138. No es posible, a través de esta referencia, averiguar la fecha de la visita.

94 Véase nota 10 supra. En algún momento el conde de Paredes consiguió del príncipe Alfonso de Ávila una versión de la condestablía de Castilla, compensando así lo confiscado a su padre por Álvaro de Luna cuando era condestable (COOPER, Edward y Mirete MAYO, Salvador, La Mitra y La Roca..., p. 71).

95 Vidal González, F., Gómez Manrique cancionero, Madrid, 2003, pp. 26-27. El parentesco de su mujer, Juana Mendoza Guzmán, con el marqués de Santillana (principal de los Mendoza), era sin embargo muy distante, no obstante el apellido. El atractivo de Molina de Aragón pudo deberse también a la posibilidad de la formación de alumbre como consecuencia de la alteración de las menas metálicas del término molinés, donde la presencia de riolitas sugeriría una génesis que se asemejaría a la del alumbre de Mazarrón, es decir, el origen volcánico.

${ }_{96}$ ACA loc. cit. 3444 fol. 34r. El lugar de expedición, el real campo contra Lérida, indica sin mucha duda que esta es la fecha del fallecimiento de Juan de Luna (COOPER, Edward y MireTE 
logía el abandono de la causa de su madre por el sobornado vástago, siendo pronto confirmada ella como adversaria del arzobispo. De su parte, el rey aragonés apoya a, o por lo menos coincide con, el arzobispo en conexión con la vacante en la sede de Sigüenza, ocurrida a finales de 146597. Entre el 11 de enero de 1466 y el 6 de abril, escribe repetidas veces a Enrique IV, prestándose a la candidatura del deán Diego López de Madrid, preferida por su «querido amigo» el arzobispo de Toledo ${ }^{98}$. El esfuerzo fue en balde, pero rey y arzobispo lograron demorar 4 meses el resultado desfavorable.

El arzobispo era sobre todo un hombre de dinastías. Incluía en el ejercicio de la primacía el papel de casamentero, y no veía ajena a la devoción pastoral la potenciación del patrimonio familiar. Su doblez en conseguir un objeto con este incentivo era comparable con la del rey aragonés ${ }^{99}$. Se puede pensar que, al no evitar ser vinculado con el asesinato, el 23 de noviembre de 1468, de Nicolás de Echávarri (obispo, finalmente, de Pamplona, y último pontífice natural del reino independiente), Carrillo se había envilecido definitivamente ${ }^{100}$. Pero hubo otros fallecimientos convenientes en su momento a los propósitos arzo-

MAYo, Salvador, La Mitra y La Roca..., p. 24). El triste destino de Álvaro de Luna, sí mismo traicionado al final (CoOPER, Edward y Mirete MAYO, Salvador, La Mitra y La Roca..., p. 34), dependió del rey de Aragón algo más de lo que parecía: mientras el interino en Cornago, Juan de Beaumont, gran prior de Navarra en la Orden de San Juan, apoyaba contra el Rey los remensas catalanes, interesaba a éste pretender amistad con Álvaro de Luna. El motivo de Beaumont, por otra parte, era claramente conseguir la vacante en la castellanía sanjuanista de Amposta, ocasionada por la ascensión del castellán Pere Ramón Sacosta a gran maestre de Rodas. Juan II pretendía destinar a Amposta a Bernat Hug de Rocabertí (en Calatayud a 6 de noviembre de 1461 (ACA loc. cit. 3361 fols. 84-7)), pero se opusieron los remensas, ocupando al efecto el mismo castillo de Amposta. Mientras duraba el asedio, se mantenían las esperanzas de Juan de Beaumont. Cedieron los defensores de Amposta en 1466. El 14 de junio, Juan II entregó el castillo y la población a Pierres de Peralta (ibid. 3356 fols. 97r.-101). Esto no era lo mismo que la castellanía, pero fue suficiente para que renunciara Juan de Beaumont. En el momento que el rey previó esta eventualidad, la vida de Álvaro de Luna, de hecho probablemente ya asesinado, había dejado de valer un rábano.

97 CoOper, Edward y Mirete Mayo, Salvador, La Mitra y La Roca..., p. 57.

98 ACA loc. cit. 3446 fols. 5v. y 79r., y 3447 fol. 26v. En la diplomática aragonesa de la época, «amado» es la designación normal de la Corona para casi cualquier persona que no sea específicamente un enemigo. El deán era seguramente de la facción hostil de los Mendoza, lo cual hace aparentemente ilógica la insistencia del arzobispo. Siendo su prioridad proteger la ocupación de Molina de Aragón (un arciprestazgo en el cabildo catedral de Sigüenza), hay que suponer que había identificado a López de Madrid como otro sobornable.

99 No obstante todo lo que se ha desarrollado en la nota 96 sobre la enemistad entre el rey y Juan de Beaumont, en Tarragona el 30 de enero de 1465 Juan II censura al alcaide de Corella, García de Aybar, y sus consortes, el no haberle entregado el castillo de Corella (ibid. 3339 fol. $35 v$.). La negativa consistorial se debía, seguramente, a presión del arzobispo de Toledo, en esa época incondicional ya, al parecer, del rey aragonés quien pensaba, talvez, desviar las ambiciones de Juan de Beaumont sobre Amposta satisfaciéndole con Corella. Lógicamente, el arzobispo habría preferido que Corella siguiera sirviendo como aliciente para que Juan de Beaumont soltara Cornago.

100 CoOPer, Edward y Mirete MAYO, Salvador, La Mitra y La Roca..., pp. 69-85. 
bispales, como el de fray Alonso de Oropesa, general de la orden de San Jerónimo e influyente voto habitual de la moderación en la política del reinado de Enrique IV, ocurrido el 22 de octubre de $1468^{101}$. Con el fracaso de la empresa de Casacarrillo, el arzobispo ya no tenía los recursos para superar a sus adversarios repartiendo sobornos.

Habiendo hecho al menos la vista gorda al homicidio, Carrillo tuvo que aguantar durante 5 años para ver instalado en la sede de Pamplona a su sobrino. Desde luego, este intervalo evitó el error diplomático que habría sido la ascensión precipitada del joven. Pero la delicadeza no era el estilo de Juan II. Más bien alternaba el premio con el castigo, siempre en su beneficio. Mientras hace esperar al arzobispo, el rey le agracia favoreciendo a su hijo bastardo Troilus, dándole en 24 de julio de 1470 el título siciliano de conde de Agosta; después estando en Tafalla, el 20 de abril de 1471, manda al baile general de Aragón, Martín de Lanuza, que apoye a Troilus en su infructuoso asedio de Motos $^{102}$. Las incesantes contiendas de estos años, a propósito relatadas aquí, fueron lo que realmente puso fin a la primera época minera en la España bajomedieval, que en cuanto al alumbre se puede denominar la pre-volcánica, de gran interés por los conocimientos de procesos y de química que supone, e ignorada por todos los que han estudiado las industrias de Tolfa y Mazarrón. Ahora supongo que se puede esperar de mi colaborador Salvador Mirete la correspondiente aclaración de los aspectos científicos de las cinco (o más) explotaciones inéditas de mediados del siglo XV en España.

Recibido: 18-09-2007

Aceptado: 11-04-2008

101 Talavera, Gabriel de, Historia de nuestra señora de Guadalupe, Toledo, 1597, libro II, cap. XXII. Oropesa había encabezado la negativa jerónima a la propuesta del Príncipe Alfonso de Ávila, de convertir esta orden de religiosos en una militar al estilo de la de Calatrava.

102 ACA loc. cit. 3451 fol. 1. La referencia no menciona siquiera el título ya ostentado por Troilus Carrillo. La torre de Motos fue tomado finalmente por el corregidor de Molina en 1474 (Archivo de la Comunidad de las Aldeas de Albarracín loc. cit. cuentas de Domingo Gómez vecino de Orihuela del Tremedal de 15 de enero de 1475 fol. 248r.). 